\title{
Stressors and Coping Mechanisms of College Scholarship Grantees: A Quantitative Case Study of an Island Higher Education Institution
}

\author{
Elein T. Esperanza ${ }^{1}$, Ferdinand Bulusan ${ }^{2, *}$ \\ ${ }^{1}$ Faculty of Psychology and Professional Education, Teacher Education Department, Batanes State College, Philippines \\ ${ }^{2}$ Faculty of English and Professional Education, Teacher Education Department, Batanes State College, Philippines
}

Received March 17, 2020; Revised April 3, 2020; Accepted April 19, 2020

Copyright $\odot 2020$ by authors, all rights reserved. Authors agree that this article remains permanently open access under the terms of the Creative Commons Attribution License 4.0 International License

\begin{abstract}
The literature is rich with studies on stressors and coping mechanisms. However, studies specifically focusing on stressors and coping mechanisms of college scholarship grantees are scarce. Scholarship grantees seem to have a different case as compared to regular college students in terms of maintaining their grade weighted average. Geographical seclusion, as a case, was not fully considered as a variable in existing studies about stressors. This study addressed this gap by hypothesizing the relationship between stressors and coping mechanisms used by college scholarship grantees in an island state college. It used a quantitative, non-experimental case study design of 262 college scholars from various courses. Using a three-part reliable questionnaire, this study found out that when faced with a certain stressor, the college scholars tend to use specific coping mechanism. Hence, a significant relationship exists between exposure to a stressor and the extent of using coping strategies. Moreover, college scholars have the greatest extent of exposure to personal social and academic stressors, as they are obliged to maintain their good academic standing to sustain their scholarship grants. Religiosity emerged to have been the most extensive coping mechanism. Results have ramifications to Guidance and Counseling, stress management program among college scholars, and future researchers along this field.
\end{abstract}

Keywords College Scholars, Higher Education, Stress Management

\section{Introduction}

Famous developmental theorists [1-2] believed that adolescence has long been considered as a period of dramatic and rapid change, accompanied by multiple psychosocial challenges. Change and challenges are evident in almost every area of growth, including physiological, cognitive, behavioral, and environmental realms [3]. These stresses include interpersonal pressures such as strains by the world to succeed, academic demands, social activities and conflicts with parents, stemming from independence and identity issues; and intrapersonal pressures such as acceptance of one's body image and sexuality, decision-making, financial responsibilities, concerns about uncertain futures, and new ideas and temptations [3]. Hence, as young people are exposed to these stresses, they are compelled to use successful yet ever-changing coping mechanisms.

Studies, therefore, prove that the coping process is a particularly important skill during adolescence because it is the first time that young people are confronted with many different types of stressors and may not yet have a wide variety of coping strategies upon which to rely on [4]. In contrast, the young adult stage is associated with the use of a broader range of coping strategies and a greater ability to view problems from multiple perspectives [5].

More than just academic strain, college students may suffer a decline in their emotional or mental health between the time they enter and finish their tertiary education [6]. Hence, this study adopts the theory developed by Lazarus [7]. The theory identifies the process of coping as critical mediators of stressful person-environment relations and their immediate and long-range outcomes. Coping, on the other hand, is defined as the cognitive and behavioral efforts to master, reduce, or tolerate those demands [7]. It was due to the differences between researches in how stress was defined, and how coping with it were different, this research has tried to provide a full understanding and more details about the meaning of stress, strain, and coping mechanisms from the past literature. 
According to Lazarus and Folkman [8], problem-focused coping includes confrontative coping, plan full problem-solving, and seeking social support. Whereas, emotion-focused coping includes self-control, distancing, positive appraisal, accepting responsibility, and escape or avoidance. Moreover, according to Carver and Weintraub [9], problem-focused coping includes active coping, planning, restraint coping, seeking social support for instrumental reasons, and suppression of competing activities. Whereas, emotion-focused coping are positive reinterpretation and growth, religion, humor, acceptance, and seeking social support for emotional reasons. Moreover, he added one more model named as dysfunctional coping. Its contents focus on venting of emotions, denial, behavioral disengagement, mental disengagement, and alcohol or drug use.

In the Asian context, Ang and Huan [10] proved that academic stress arising from adolescents' self-expectations and expectations of others (e.g., parents and teachers) is particularly salient. The body of literature is rich with empirical studies about college students who fail to respond successfully to stresses through appropriate coping mechanisms. Such failure results to a latitude of psychosocial problems like poor academic performance [11], anxiety [12], depression [13-15], mental distress [16], eating disorders [17] and alcohol use [18].

However, the literature is scarce about college students who are recipients of the scholarship and financial assistance. Scholarship grantees are more pressured in terms of maintaining their grade weighted average (GWA). The maintenance of the GWA is the prime requirement to sustain their scholarship. Moreover, there is also a paucity of literature conducted on island higher education institutions. Geographic seclusion [19-20] is also found to be an emerging stressor. The case of an island state college is of paramount importance in contributing to the newness of perspective in research.

This study aimed to address the mentioned literature gaps on stressors and coping mechanisms of scholarship grantees in a geographically detached higher education institution. It, specifically, answered the following questions:

1. To what extent do the scholarship grantees experience various stressors?

2. What is the extent of the use of coping mechanisms among the college scholarship grantees?

3. Is there a significant relationship between the scholarship grantees' exposure to stressors and their coping mechanisms?

This study is significant to scholarship funders, higher educational institutions, and guidance counselors. The results of the study are hoped to provide baseline reasons in improving guidelines and emotional student support to the scholarship grantees. Moreover, the results may be used to create stress management interventions for the scholarship grantees, especially those that live in geographically secluded higher education institutions.

\section{Materials and Methods}

\subsection{Research Design}

This study is a non-experimental case study. Specifically, it made use of a quantitative case study. Yin [21] has argued that whereas survey research relies on statistical generalization, case studies rely on analytical generalization. Thus, the researchers aimed to generalize a particular set of results to some broader theory. In this study of the stressors and coping mechanisms of an island state-owned higher education institution, all characteristics of a case study design were met, namely: specificity, descriptive, inductive, boundaries, and willing participants. Concerning specificity, Marshall and Rossman [22] mentioned that a case study should relate to "specific organization, program or process" (p. 164). With regard to boundaries, Stake [23] stressed that a case study must always have boundaries. He also mentioned that it is important to select cases in which the subjects are willing to participate. In this study, the specific organization and boundaries are chosen in an island state-owned college

\subsection{Participants}

Since this research is a quantitative case study, participants were only limited to 262 college scholars of one island state-owned tertiary institution. They were all under the following scholarship programs: Grant-In-Aid-Program, Expanded Scholarship Grant Program for Poverty Alleviation (ESGPPA), Agricultural Competitiveness Enhancement Fund (ACEF), Department of Science and Technology (DOST), Commission on Higher Education Full Merit (CHEd), scholarships for Miss Batanes State College, Supreme Student Council President (SSC), National Commission for Indigenous Peoples (NCIP) and Iskolar ng Bayan. Purposive-stratified sampling technique was employed to arrive at the total sample size. Of the 262 participants, 152 were 15 to 19 years old, and the rest were 20 years old and above. Meaning, most of the participants were teenagers.

\subsection{Research Instrument}

The research instrument used in this study was a survey questionnaire with three parts. The first part focused on the participants' personal background; the second part was the stressor questionnaire, while the third part concentrated on the coping mechanisms. The stressor questionnaire was adopted from Nikakul [24], while the coping mechanism questionnaire was adopted from Carver [25]. To suit the context of the participants, the researchers modified the questionnaire. Hence, before its administration, the 
questionnaire went through reliability testing by computing its Cronbach alpha [26]. It resulted in .862, interpreted as having "good internal consistency." The scholars who participated in the pilot testing were excluded from the actual data gathering.

In the stressor questionnaire, seven domains were included, namely: personal-social, home and family relations, health and physical conditions, financial, academic, career and leisure. The coping mechanism questionnaire, on the other hand, was categorized into the following scales: positive reinterpretation and growth, mental disengagement, focus on and venting of emotions, use of instrumental social support, active coping, denial, religious coping, humor, behavioral disengagement, restraint, use of emotional support, substance use, acceptance, suppression of competing activities, and planning.

\subsection{Data Collection Procedures}

Prior to the administration of the actual questionnaire, the researchers sought permission from the college president. The venue and schedule were set according to availability and convenience of the participants. Before the participants answered each item, the researchers had succinctly discussed the questionnaire and the purpose of the study. That was done to avoid any misinterpretation of an item. There was a $100 \%$ response rate.

\subsection{Ethical Considerations}

When permission was granted, the researchers discussed the informed consent with the participants. Salient components of the consent included the assurance of confidentiality, the participants' right to withdraw and withhold the data, and the assurance of anonymity [27]. Hence, during the data analysis, profiles of the participants were not known because participant IDs were used.

\subsection{Data Analysis}

The collected set of data was coded, tallied, and cleaned in an electronic spreadsheet. Thus, outliers were detected and later deleted. To answer the first two research questions, frequency count, percentile rank, and arithmetic mean were computed using the Statistical Package for Social Sciences (SPSS) software. Meanwhile, Pearson product-moment correlation was employed to determine the significant relationship between the stressors and the coping mechanisms of the participants in various situations, using a 0.05 level of significance. The succeeding arbitrary scale was used to interpret the extent of the stressors experienced by the college scholars and the extent of using various coping mechanisms.
Table 1. Arbitrary Scale

\begin{tabular}{|l|l|l|}
\hline Scale & $\begin{array}{l}\text { Adjectival Description } \\
\text { (Extent of Stressors) }\end{array}$ & $\begin{array}{l}\text { Adjectival Description } \\
\text { (Extent of Use of Coping } \\
\text { Mechanisms) }\end{array}$ \\
\hline $4.20-5.00$ & Very True & To a Very Large Extent \\
\hline $3.40-4.19$ & True & To a Large Extent \\
\hline $2.60-3.39$ & Quite True & To a Moderate Extent \\
\hline $1.80-2.59$ & Somewhat True & To a Small Extent \\
\hline $1.00-1.79$ & Not True & To a Very Small Extent \\
\hline
\end{tabular}

\section{Results}

This study inquired on what stressors do the college scholarship grantees experience and the extent of using coping mechanisms. Also, it hypothesized that there is no relationship between the stressors and coping mechanisms the participants used.

It can be gleaned in Table 2 the extent to which the scholarship grantees encountered the seven primary stressors. Among the stressors, the scholarship grantees experience personal-social (2.67) and financial (2.64) as the highest forms of stressors. They are both descriptively interpreted as "Quite True." Meanwhile, health and physical condition (1.75) is the lowest experienced stressor. It is descriptively interpreted as "Somewhat True." Because five out of seven stressors fall within the "somewhat-true" range, the general weighted mean is 2.22 , translated as somewhat true.

Table 2. Exposure of the Scholarship Grantees to Stressors

\begin{tabular}{|l|c|l|}
\hline Stressors & Category Mean & $\begin{array}{l}\text { Descriptive } \\
\text { Interpretation }\end{array}$ \\
\hline Personal-social stressor & 2.67 & Quite True \\
\hline $\begin{array}{l}\text { Home and family } \\
\text { relations stressor }\end{array}$ & 1.84 & Somewhat True \\
\hline $\begin{array}{l}\text { Health and physical } \\
\text { conditions stressor }\end{array}$ & 1.75 & Somewhat True \\
\hline Financial stressor & 2.64 & Quite True \\
\hline Academic stressor & 2.21 & Somewhat True \\
\hline Vocational stressor & 2.35 & Somewhat True \\
\hline Leisure stressor & 2.07 & Somewhat True \\
\hline \multicolumn{1}{|c|}{ Grand Mean } & 2.22 & Somewhat True \\
\hline
\end{tabular}

Table 3 shows the extent of the use of coping mechanisms by the scholarship grantees. Of the 15 coping strategies, the college scholarship grantees listed religious coping (3.15) and positive reinterpretation and growth (3.01) with the highest mean scores, respectively. However, these coping strategies still lie within the range of a moderate extent. Nine among the 15 were rated a moderate extent. The lowest mean among the stressors is substance use (1.58). The computed grand mean on the extent of use of coping mechanisms is 2.57 , translated to a small extent. 
Table 3. Extent of use of the Coping Mechanisms

\begin{tabular}{|l|l|l|}
\hline $\begin{array}{l}\text { Coping } \\
\text { Mechanisms }\end{array}$ & Mean & $\begin{array}{l}\text { Descriptive } \\
\text { Interpretation }\end{array}$ \\
\hline $\begin{array}{l}\text { Positive Reinterpretation } \\
\text { and Growth }\end{array}$ & 3.01 & to a moderate extent \\
\hline Mental Disengagement & 2.48 & to a moderate extent \\
\hline $\begin{array}{l}\text { Focus on and Venting of } \\
\text { Emotions }\end{array}$ & 2.56 & to a moderate extent \\
\hline $\begin{array}{l}\text { Use of Instrumental Social } \\
\text { Support }\end{array}$ & 2.82 & to a moderate extent \\
\hline Active Coping & 2.80 & to a moderate extent \\
\hline Denial & 2.28 & to a small extent \\
\hline Religious Coping & 3.15 & to a moderate extent \\
\hline Humor & 2.36 & to a small extent \\
\hline Behavioral Disengagement & 2.46 & to a small extent \\
\hline Restraint & 2.50 & to a small extent \\
\hline Use of Emotional Support & 2.63 & to a moderate extent \\
\hline Substance use & 1.58 & to a very small extent \\
\hline Acceptance & 2.64 & to a moderate extent \\
\hline $\begin{array}{l}\text { Suppression of Competing } \\
\text { Activities }\end{array}$ & 2.54 & to a small extent \\
\hline Planning & 2.81 & to a moderate extent \\
\hline Grand Mean & 2.57 & to a small extent \\
\hline
\end{tabular}

Table 4 shows the relationship of the stressors (rows) and the coping mechanisms (columns) of the scholarship grantees. Pearson's product-moment correlation was calculated. It yielded a small to medium positive correlation between the financial stressor and 12 coping strategies. It should be noted that positive correlation means that as one variable gets larger, the other gets larger. In the table, the highest correlation coefficient is seen between vocational stressor and denial as a coping strategy $(\mathrm{r}=.323)$. They have a moderately positive correlation. Financial and use of emotional support have garnered the lowest correlation coefficient $(r=122)$, interpreted as having a positive weak correlation. Furthermore, the table reveals that among the 12 significantly correlated coping mechanisms, the focus on venting of emotions has the highest correlational value $(r=0.274)$.

Meanwhile, it is observed that there is no significant relationship that exists when Family and Home Relations is correlated with different coping mechanisms. The data also reveals that the first stressor on Personal-Social has a significant relationship to the following coping mechanism such as mental disengagement, focus on and venting of emotions, denial, behavioral disengagement, restraint coping, and suppression and competing activities.

Results also revealed that eight coping mechanisms have been proven to affect academic stress significantly. Furthermore, the table shows that among the eight coping mechanisms, denial has the highest correlational value $(r=0.317)$. Table 4 shows that among the 15 coping mechanisms, nine manifested a significant correlation between vocational stress.

Table 4. Test of Significant Relationship between Students' Stressors and Coping Mechanisms

\begin{tabular}{|c|c|c|c|c|c|c|c|}
\hline \multirow{2}{*}{ Variables } & PS & HFR & HPC & $\mathbf{F}$ & $\mathbf{A}$ & $\mathbf{V}$ & $\mathbf{L}$ \\
\hline & $r$ value & $r$ value & $r$ value & rvalue & rvalue & $r$ value & rvalue \\
\hline Positive Reinterpretation and Growth & -- & -- & -- & $.207 * *$ & -- & -- & -- \\
\hline Mental Disengagement & $.168^{* *}$ & -- & $.214 * *$ & $.162 * *$ & $.175^{* *}$ & $.229 * *$ & $.200 * *$ \\
\hline Focus on Venting of Emotions & $.203 * *$ & -- & $.199 * *$ & $.274 * *$ & $.222 * *$ & $.262 * *$ & $.164 * *$ \\
\hline Use of Instrumental Social Support & -- & -- & -- & -- & -- & -- & -- \\
\hline Active Coping & -- & -- & -- & $.191 * *$ & -- & -- & -- \\
\hline Denial & $.306^{* *}$ & & $.195 * *$ & $.239 * *$ & $.317 * *$ & $.323 * *$ & $.304 * *$ \\
\hline Religious Coping & -- & -- & -- & -- & -- & -- & -- \\
\hline Humor & -- & -- & $.244 * *$ & -- & $.193 * *$ & $.172 * *$ & $.238 * *$ \\
\hline Behavioral Disengagement & $.274 * *$ & -- & -- & $.207 * *$ & $.267 * *$ & $.219 * *$ & $.275 * *$ \\
\hline Restraint & $.180^{* *}$ & -- & -- & $.233 * *$ & $.180^{* *}$ & $.162 * *$ & $.210 * *$ \\
\hline Use of Emotional Support & -- & -- & $.149 * *$ & $.122 * *$ & $.137 * *$ & $.209 * *$ & $.140 * *$ \\
\hline Substance use & -- & -- & $.187 * *$ & $.150 * *$ & $.201 * *$ & $.169 * *$ & $.216^{* *}$ \\
\hline Acceptance & -- & -- & & $.149 *$ & & & \\
\hline Suppression of Competing Activities & $.143 * *$ & -- & $.158 * *$ & $.228 * *$ & $.186^{* *}$ & $.144 * *$ & $.172 * *$ \\
\hline Planning & -- & -- & -- & $.170 * *$ & -- & -- & -- \\
\hline
\end{tabular}

**Significant at 0.05 
Statistically, there is enough evidence to state a significant, moderately positive correlation between vocation stresses and coping mechanisms. These coping mechanisms revealed a significant effect of vocational stressors, but, among them, denial emerged to have the strongest correlation with vocation stress as it has the highest correlational value $(r=0.323)$.

A significant positive correlation between leisure and the other nine coping mechanisms. They include mental disengagement focus on venting of emotions, denial, humor, behavioral disengagement, restraint coping, use of emotional support, substance use, and suppression using 0.05 value of alpha. Furthermore, with the analysis made, it was revealed that denial has the highest correlational value $(r=304)$ as a coping mechanism to address vocational stress.

\section{Discussion}

This quantitative case study aimed to find out the relationship between the stressors and coping mechanisms of college scholarship grantees in an island state-owned institution, which is geographically detached from the mainland Luzon in the Philippines. The researchers first identified the extent of the participants' experiences on the stressors and their use of coping mechanisms.

Generally, the scholarship grantees "somewhat experience" the seven stressors. With an overall mean of 2.67 and described as Quite True, the scholarship grantees usually have observed the existence of personal and social problems as a natural attribution to life. Only that there should be assistance from the community to help them get rid of these problems. This aligns with the studies of Elliot and Gramling [28] Macgeorge, Samter, \& Gillihan [29], and Singh [30]. They claimed that college students having a great social circle could hamper stress and improve resilience. Such a social network can also decrease academic stress.

Some family issues are observed to be less likely experienced by the scholarship grantees. Meaning, there are no severe problems they feel against their family. Moreover, "Health and Physical Condition" is not entirely perceived as a stressor. Statistically, there is no enough evidence or indication that health problems or issues are challenging the students. It can be explained, therefore, that the health and physical conditions of the students are adequately maintained and given utmost attention. One main reason is that they are aware of the pros and cons of having weak body resistance that may affect their daily practice or even their health and studies.

Academic is considered a factor that drives students to feel uncomfortable with their learning environment. It can be dealt with further that as a scholar, good grades must become their primordial consideration or goal in order to maintain the grants provided. Students who are conscious of this policy are, therefore, afraid of losing an opportunity to study with financial aid coming from private and public organizations. It further suggests that no matter what happens, that despite all the challenges these students will encounter in their degree, they still have the strong sense that they will not eventually give up in order to defend and justify their scholarship privileges. This is consistent with the study of Waghachavare, Dhumale, Kadam, and Gore [31], claiming that college students experienced a certain level of stress associated with academic factors.

In terms of their coping mechanism, religious coping refers to the use of religion or spiritual guidance as a vehicle for positive reinterpretation and growth. This reflects the pious nature of Filipinos that they cling to an Omnipotent Being when they are confronted with stressors. It is also consistent with the study of Qidwai, Tabassum, Hanif, and Khan [32] that most people use prayer to cope with stress and maintain good holistic health. Other studies [33-34] proved that religious involvement positively affects good health and is inversely related to distress.

Furthermore, among the 15 indicators, substance use is the least used coping mechanism with only a 1.58 mean rating. This implies that the grantees resort to substance use to a very small extent only. Hence, it suggests that most of the scholarship grantees do not find substance (alcohol, tobacco, or drugs) use as a good coping mechanism. This is consistent with the study of Pierceall and Keim [35]. However, it is inconsistent with the study of Bottorff, Johnson, Moffat, and Mulvogue [36]. The latter found that adolescent students use substance abuse like marijuana for stress relief.

Denial as a coping mechanism has the most significant correlational value of 0.306 as compared to other mechanisms. It implies that most of the respondents view denial as an ultimate way to overcome personal, social, and emotional challenges. Denial means trying to protect oneself by refusing to accept the truth about something that is happening in one's life. In the context of dealing with academic predicaments, the college scholarship grantees deny the existence of such a problem to reduce stress. Among the nine statistically significantly correlated coping mechanisms to leisure, denial also has the most significant relationship with the latter. It denotes that most of the scholarship grantees resort to using denial or ignoring the existence of leisure stress as a way to respond to the problem to reduce stress. Denial is beneficial at some point, but in the long run, it can cause some serious problems since it prevents one from dealing with issues that require action. In fact, Metzger et al. [37] claimed that students who generally use denial as a maladaptive coping strategy might be at increased risk of problematic behavioral and psychological outcomes, including problematic alcohol use. This implies the needs of the college scholarship grantees to be needing intervention in facing personal, social, and emotional stressors. 
The college scholarship grantees tend to rest on the stated mechanisms that have a great effect on coping with their weaknesses. The social environment is a significant contributory factor that causes challenges, and thus the school must take part in helping these students overcome their loopholes. This finding is being supported by Ramsay, Jones, and Barker [38], who noted that there is value in allowing students to face challenges; students also need support during times of transition. College students need to be able to see that their school's environment offers them support to reduce the stress associated with transitioning into a challenging environment.

There is no significant relationship that exists when family and home relations are correlated with different coping mechanisms. Meaning, the college scholarship grantees have encountered minuscule or not so grievous anxieties that do not require them to display the use of managing mechanisms to overcome the situations. Taking the positive side of this outcome, these scholars can manage themselves when confronted with issues in their respective families. It also stresses out that parents maintain intimate involvement in rearing up their children and undoubtedly modeled appropriate parental practices that influenced their children to adopt it positively. In support of this claim, the same perception is highlighted by the study conducted by Steinberg [39] that parental involvement in a child might have lasting effects on its behavior. It also asserts that conflict is a critical aspect of family functioning that often outweighs the influence of family structure on the child's development. He also reports that studies carried out have found that children's health and social development is most effectively promoted by love and at least some reasonable parental control.

Evidently, humor has the highest value of the correlation coefficient. It can be inferred that in most cases, they try to hide their physical conditions or generally, their health problems. They do it by spending their time with so much happiness, acts of humor, or even becoming humorous to others in order to ease the pain brought about by their physical conditions. Venting of emotions is the most used mechanism to respond to the financial stress that respondents are facing. It signifies that venting financial stress to others lightens up their financial burdens.

\section{Conclusions and Implications}

Focused on college scholarship grantees, this quantitative case study found some significant relationship between the exposure of stressors and the extent of use of coping mechanisms. When faced with a particular stressor, they tend to use specific coping mechanisms. For instance, when their career choice or vocation stresses them, they tend to use denial as a coping mechanism. It has also found out that college scholars have the greatest extent of exposure to personal social and academic stressors, as they are obliged to maintain their good academic standing to sustain their scholarship. The fact is that most of the participants in this study were teenagers and on the transition period of childhood to adulthood, it is no surprise that they are most probably confronted with personal-social stressors. Furthermore, it was discovered that the most used coping mechanism in this Filipino was religious coping. This speaks to the pious nature of the Filipinos that whenever they are confronted with problems, they lift them all up to the Highest Being. Resorting to substance use (e.g., alcohol, marijuana, cigarette, and the like.) would be the least choice of coping mechanism among the scholarship grantees.

Meanwhile, the results of this study could have ramifications in the Guidance and Counseling Services of the study site. It might want to consider the results in crafting a stress-management program for scholarship grantees. The program may focus on improving dysfunctional coping mechanisms of the scholarship grantees.

This study posits some limitations. First, it only used a quantitative approach, which may be lacking substantial reasons to explain the phenomenon. Future researchers may, therefore, want to use qualitative designs or a combination of both designs (mixed-methods) to add flesh to this case. Second, it is a single-case study; hence, the generalizability is weak. A multi-site study of comparative cases may be best considered to strengthen the evidence of determining causality and relationships. Third, the stressors are coping mechanisms that are lifted from a scale crafted outside the Philippines. Even if the questionnaires were slightly modified, perhaps, a study may yield a different set of findings if the stressor and coping scales are crafted using the context of the Filipinos. Thus, future researchers may want to develop a scale of stressors and coping mechanisms focusing on tertiary students in the Philippines and considering the peculiarities of the Filipino culture.

\section{REFERENCES}

[1] Erikson, E.H. Identity: youth and crisis. Norton \& Co. 1968.

[2] Piaget, J. Intellectual Evolution from Adolescence to Adulthood. Human Development, Vol. 15, 9-12.

[3] Landow, M. V. Stress and mental health of college students. New York: Nova Science Publishers, 2006.

[4] Patterson, J. M., McCubbin, H. I. Adolescent coping style and behaviors: Conceptualization and measurement. Journal of Adolescence, Vol. 10, No. 2, 163-186.

[5] Seiffge-Krenke, I. Research monographs in adolescence. Stress, coping, and relationships in adolescence. Lawrence Erlbaum Associates, Inc. 1995

[6] Dyson, R, Renk, K. Freshmen adaptation to university life: 
depressive symptoms, stress, and coping. Journal of Clinical Psychology, Vol. 62, No. 10, 1231-1244.

[7] Lazarus R. S. Emotions and interpersonal relationships: toward a person-centered conceptualization of emotions and coping. J. Pers. Vol. 74, 9-46.

[8] Lazarus R. S., Folkman S. Stress, Appraisal and Coping. New York: Springer. 1984.

[9] Carver, C. S., Scheier, M. F., Weintraub, J. K. Assessing coping strategies: A theoretically based approach. Journal of Personality and Social Psychology, Vol. 56, No. 2, 267-283.

[10] Ang P., Huan S. Relationship between academic stress and suicidal ideation Testing for depression as a mediator using multiple regression. Child psychiatry and human development. Vol. 7, No. 2, 133-143.

[11] Struthers, C.W., Perry, R.P., Menec, V.H. An Examination of the Relationship Among Academic Stress, Coping, Motivation, and Performance in College. Research in Higher Education. Vol. 41, 581-592.

[12] Smith, T., Renk, K. Predictors of academic-related stress in college students: an examination of coping, social support, parenting, and anxiety. NASPA Journal, Vol. 44, 405-431.

[13] Bouteyre, E., Maurel, M., \& Bernaud, J.-L. Daily hassles and depressive. 2007.

[14] Ogul, M., Gençoz, T. Roles on perceived control and coping strategies on depressive and anxiety symptoms of Turkish adolescents. Psychological Reports, Vol. 93, No. 3, 659672.

[15] Steinhardt, M., Dolbier, C. Evaluation of a Resilience Intervention to Enhance Coping Strategies and Protective Factors and Decrease Symptomatology. Journal of American College Health, Vol. 56, 445-453.

[16] Yamasaki, M., Sasaki, Y. Determining Young's modulus of timber on the basis of a strength database and stress wave propagation velocity I: an estimation method for Young's modulus employing Monte Carlo simulation. J Wood Sci. Vol. 56, 269-275.

[17] Wichianson, J. R., Bughi, S. A., Unger, J. B., Spruijt-Metz, D., Nguyen-Rodriguez, S. T. Perceived stress, coping and night-eating in college students. Stress and Health: Journal of the International Society for the Investigation of Stress, Vol. 25, No. 3, 235-240.

[18] Pritchard, M., Wilson, G., Yamnitz, Ben. "What Predicts Adjustment Among College Students? A Longitudinal Panel Study". Journal of American College Health, Vol. 56, No. 1, 15-21.

[19] Epel, E. S., Crosswell, A. D., Mayer, S. E., Prather, A. A., Slavich, G. M., Puterman, E., \& Mendes, W. B. More than a feeling: A unified view of stress measurement for population science. Frontiers in Neuroendocrinology. 2018.

[20] Koffer, R. E., Ram, N., Conroy, D. E., Pincus, A. L., Almeida, D. M. Stressor diversity: Introduction and empirical integration into the daily stress model. Psychology and Aging. 2016.

[21] Yin, R. K. Case study research (4th ed.). Thousand Oaks, CA: Sage. 2009.
[22] Marshall, C., Rossman, G. B. Designing qualitative research (4th ed.). Thousand Oaks, CA: Sage. 2006.

[23] Stake, R. The art of case research. Thousand Oaks, CA: Sage. 1995.

[24] NIkakul, F. Stressors and coping mechanisms of students. Unpublished Master's Thesis. 2007

[25] Carver, C. S., Scheier, M. F., Weintraub, J. K. Assessing coping strategies: A theoretically based approach. Journal of Personality and Social Psychology, Vol. 56, No. 2, 267-283.

[26] Bulusan, F., Antonio, R., Dumaga, S. Correct Me If I'm Wrong: Exploring the Attitudes and Preferences of ESL Learners on Oral Corrective Feedback in A Multicultural Milieu. ASIAN ESP, Vol. 15, No. 2, 83-104.

[27] Bulusan, F. College ESL Learners' Politeness in Using Linguistic Taboos and Euphemisms: Looking Through the Socio-Pragmatic Lens. International Journal of English Linguistics. Vol. 9, No. 3, 148-157.

[28] Elliott, T. R., Gramling, S. E. Personal assertiveness and the effects of social support among college students. Journal of Counseling Psychology, Vol. 37, No. 4, 427-436.

[29] MacGeorge, E. L., Samter, W., Gillihan, S. J. Academic stress, supportive communication, and health. Communication Education, Vol. 54, 365-372.

[30] Singh, P. Bridging Social Group in Coping Psychological Problems. International Journal of Engineering Technology, Management and Applied Sciences, Vol. 4, No. 1, 108-112.

[31] Waghachavare, V. B., Dhumale, G. B., Kadam, Y. R., Gore, A. D. A study of stress among students of professional colleges from an urban area in India. Sultan Qaboos University Med J. Vol. 13, No. 3, 429-436.

[32] Qidwai, W., Tabassum, R., Hanif, R., Khan, F. H. Belief in prayers and its role in healing among family practice patients visiting a teaching hospital in Karachi, Pakistan. Pakistan Journal of Medical Science, Vol. 25, No. 2, 182-189.

[33] Ellison, C., Boardman, D. J., Williams, D., Jackson, S. J. Religious Involvement, Stress, and Mental Health: Findings from the 1995 Detroit Area Study. Social Forces, Vol. 80, No. 1, 215-249.

[34] Fabricatore, N. A., Handal, P., Fenzel, M. Personal spirituality as a moderator between stressors and subjective well-being. Journal of psychology and theology. Vol. 28, No. 3, 221-228.

[35] Pierceall, E. A., Keim, M. C. Stress and Coping Strategies Among Community College Students. Community College Journal of Research and Practice, Vol. 31, No. 9, 703-712.

[36] Bottorff, J. L., Johnson, J. L., Moffat, B. M., Mulvogue, T. Relief-oriented use of marijuana by teens. Substance Abuse Treatment, Prevention, and Policy. Vol. 4, No. 1, 7.

[37] Metzger, I. W., Blevins, C., Calhoun, C. D., Ritchwood, T. D., Gilmore, A. K., Stewart, R., Bountress, K. E. An examination of the impact of maladaptive coping on the association between stressor type and alcohol use in college. Journal of American College Health. 
[38] Ramsay S., Jones E., Barker M. Relationship between adjustment and support types: Young and mature-aged local and international first year university students. Higher Education. Vol. 54, 247-265.

[39] Steinberg, L. Beyond the classroom: Why school reform has failed and what parents need to do. New York: Simon \& Schuster. 1996. 